\title{
Dissolution Rates of Calcium Boluses and Their Effects on Serum Calcium in Dairy Cattle
}

This article was published in the following Dove Press journal:

Veterinary Medicine: Research and Reports

\author{
Walter Verhoef ${ }^{\prime}$ \\ Sjoert Zuidhof ${ }^{2}$ \\ Brenda Ralston ${ }^{3}$ \\ Joseph A Ross (D) ${ }^{4}$ \\ Merle Olson (iD ${ }^{5}$
}

'Bureau Vétérinaire de Richmond, Richmond, Quebec, Canada; ${ }^{2}$ Sjoert Zuidhof Consulting, Okotoks, Alberta, Canada; ${ }^{3}$ Alberta Agriculture and Forestry, Airdrie, Alberta, Canada; ${ }^{4}$ Chinook Contract Research Inc., Airdrie, Alberta, Canada; ${ }^{5}$ Alberta Veterinary Laboratories, Calgary, Alberta, Canada
Correspondence: Walter Verhoef Bureau Vétérinaire de Richmond, 44 Rue Des Cèdres, Richmond, QC, JOB 2H0, Canada

Tel + 819-2|2-409|

Email verhoefw@videotron.ca
Purpose: Calcium supplement boluses vary greatly in content and bioavailability. Methods: In vivo dissolution and bioavailability studies were conducted to compare commercial calcium supplement boluses with various contents of calcium chloride and calcium carbonate. The products studied included: Bolus 1 (high calcium chloride, no calcium carbonate), Bolus 2 (medium calcium chloride, medium calcium carbonate), and Bolus 3 (low calcium chloride, high calcium carbonate). A bolus was placed in a preweighed coarse mesh net for $30,60,90,120,180$, and 240 minutes to measure dissolution rates in the rumen of fistulated animals. To measure calcium uptake, 27 Holstein cows (second and third lactation) were randomly allocated to one of three oral calcium protocols: Treatment 1 (two high calcium chloride boluses at time 0); Treatment 2 (one high calcium chloride bolus at time 0 with a second bolus 12 hours later); or Treatment 3 (two high calcium carbonate boluses at time 0). Treatments were initiated within 12 hours following calving and this was considered time 0 .

Results: Bolus 1 was the quickest to dissolve ( $<90$ minutes), followed by Bolus $2(<240$ minutes). The high calcium carbonate bolus (Bolus 3) remained after 240 minutes in vivo with a minimum of $75 \%$ of the original bolus weight still intact. Cows with severe hypocalcemia $(<1.8 \mathrm{mmol} / \mathrm{L})$ responded with a higher serum calcium increase than cows with milder hypocalcemia $(>1.8 \mathrm{mmol} / \mathrm{L},<2.12 \mathrm{mmol} / \mathrm{L})$. The high calcium carbonate bolus group (Treatment 3 ) did not show a rapid increase in serum calcium as compared to the high calcium chloride groups (Treatments 1 and 2). The animals receiving Treatment 1 had a greater and more persistent serum calcium response than animals receiving Treatment 2.

Conclusion: The study outcome suggests that calcium chloride/calcium sulfate boluses are more effective at generating a serum calcium response than boluses containing high amounts of calcium carbonate and that two boluses administered rapidly after calving may be more effective than the traditional treatment of giving 2 boluses 12 hours apart.

Keywords: sub-clinical hypocalcemia, milk fever, calcium chloride, calcium carbonate, calcium bolus, dissolution

\section{Introduction}

The onset of lactation results in a sudden and considerable demand for calcium, imposing arduous physiologic challenges to calcium homeostasis in dairy cows. ${ }^{1}$ Cows that are unable to adapt to this change in calcium demand develop hypocalcemia. Cows with hypocalcemia (colloquially referred to as "milk fever") present with weakness, depression, inappetence, and an inability to rise. ${ }^{1}$ Cows with clinical hypocalcemia are more likely to develop secondary mastitis, as well as muscle and nerve damage from prolonged periods of recumbency. ${ }^{2}$ As the condition name would suggest, subclinical hypocalcemia shows no overt clinical signs in 
affected animals, despite low blood calcium; however, there are other negative health consequences. Hypocalcemia reduces the ability of immune cells to respond to stimuli, thus contributing to infections, such as mastitis or metritis. ${ }^{3,4}$ Hypocalcemia also reduces smooth muscle contraction, ${ }^{5}$ which can result in reduced rumen and abomasal motility, leading to reduced feed intake and subsequent transition disorders (displaced abomasum, mastitis, metritis, retained fetal membranes, ketosis, etc). ${ }^{6}$ Subclinical hypocalcemia has also been shown to negatively affect early lactation milk production and reproduction. ${ }^{7}$ An increased culling rate was also observed for animals with subclinical hypocalcemia. ${ }^{8}$ Clinical hypocalcemia may occur in up to $5-10 \%$ of dairy cows, whereas its subclinical form is more prevalent, with estimates ranging up to $50 \%$ of mature fresh cows. ${ }^{9}$ Some authors have estimated the overall economic cost of subclinical hypocalcemia to be 4 times that of clinical cases, resulting in a substantial impact on the profitability of dairy operations. ${ }^{10}$

Several strategies have been studied to enhance the ability of periparturient dairy cows to maintain calcium homeostasis. These practices include limiting total calcium intake prepartum (which may be difficult to achieve), adding a calcium chelator to the prepartum transition ration, and modifying the dietary cation-anion difference (DCAD) by feeding anionic salts prepartum, which has become the mainstay in many herds. Oral supplementation of calcium at calving has proven effective in reducing clinical milk fever. ${ }^{11}$ Research has shown that, even in very well-managed herds with a low incidence of clinical hypocalcemia, oral calcium supplementation may have health, reproductive, and increased production benefitsmost notably in lame and high producing cows. ${ }^{12-14}$

There are several commercial boluses with substantial differences in composition, primarily with calcium chloride, calcium sulfate, and calcium carbonate. The dissolution properties of the commercial boluses will affect the delivery of product to the animal. Moreover, not all calcium salts are absorbed by the animal in the same manner. Calcium chloride and calcium sulfate are absorbed through the rumen wall by passive transport, whereas calcium carbonate is absorbed in the small intestine by vitamin D-dependant active transport. ${ }^{15}$ In addition, the acidogenic properties of calcium chloride and calcium sulfate stimulate parathyroid hormone $(\mathrm{PTH})$ function, thereby increasing calcium resorption from bone, kidney tubular reabsorption of calcium, as well as absorption of calcium in the intestine. ${ }^{16}$

In order to evaluate differences in bolus composition with respect to calcium delivery, this study measured the dissolution times of three different boluses in fistulated animals and the in vivo uptake of two calcium sources utilizing two administration protocols.

\section{Materials and Methods In vivo Dissolution Rates of Commercial Calcium Boluses}

The dissolution rate was evaluated for three commercially available boluses, each with different calcium chloride and calcium carbonate compositions: Bolus 1 (high calcium chloride, no calcium carbonate bolus): 209-g Bolus supplying $43 \mathrm{~g}$ of calcium from $112 \mathrm{~g}$ of calcium chloride dihydrate and $53.6 \mathrm{~g}$ of calcium sulfate (Cal-Boost Bolus, Solvet Animal Health, Calgary, Alberta, Canada); Bolus 2 (intermediate calcium chloride, intermediate calcium carbonate bolus): 176-g Bolus supplying $39.0 \mathrm{~g}$ of calcium from $106.9 \mathrm{~g}$ of calcium chloride, $4.5 \mathrm{~g}$ of calcium propionate, and $22.3 \mathrm{~g}$ of calcium carbonate (Transition Bolus, Vetoquinol N.-A Inc, Lavaltrie, Quebec, Canada); and Bolus 3 (low calcium chloride, high calcium carbonate bolus): 206-g Bolus supplying $54 \mathrm{~g}$ of calcium from $92.2 \mathrm{~g}$ of calcium chloride and $72.8 \mathrm{~g}$ of calcium carbonate (RumiLife CAL24 Bolus, Genex Cooperative Inc, Shawano, Wisconsin, USA). Table 1 shows the composition of these boluses. The research facility provided two fistulated steers, approximately 28 months of age and weighing $450 \mathrm{~kg}$, 1-year post-cannulation. The steers were housed in an open-air feedlot pen approximately 18 meters deep and 36 meters wide and fed a total mixed ration (TMR) including barley silage, minerals, and vitamins from a feed mixer truck once daily (late afternoon) in a cement feed bunk upon the completion of the bolus study each day. Well water was supplied ad libitum from an automatic cattle waterer. A bolus was placed in a preweighed coarse mesh net with a recovery cord. The net and bolus were then placed in the rumen through a fistula. A pretreatment $\mathrm{pH}$ was determined using $\mathrm{pH}$ strips $(\mathrm{pH}$ Test Strips, EMD Millipore) and a $\mathrm{pH}$ meter (LRCpH logger, DASCOR Inc., Oceanside, California, USA). After 30, 60, 90, 120, 180, and 240 minutes, the bolus was recovered, weighed, described, and photographed. The recovered bolus was then returned to the rumen. The rumen $\mathrm{pH}$ was determined at each sampling time using $\mathrm{pH}$ 
Table I Composition of the Commercially Available Boluses Used in This Study

\begin{tabular}{|c|c|c|c|}
\hline \multirow[t]{2}{*}{ Component } & \multicolumn{3}{|l|}{ Content (g) } \\
\hline & Cal-Boost (Bolus I) & Transition (Bolus 2) & RumiLifeCal24 (Bolus 3) \\
\hline Calcium chloride $^{\mathrm{a}}$ & 112.0 & 106.9 & 92.16 \\
\hline Calcium sulfate & 53.6 & & \\
\hline Calcium carbonate & & 22.26 & 72.76 \\
\hline Calcium propionate & & 4.48 & \\
\hline Magnesium oxide & & & 4.72 \\
\hline Vitamin D & 1.25 & 1.25 & \\
\hline Total $\mathrm{Ca}^{2+}$ & 43.0 & 39.0 & 54.3 \\
\hline Rapidly Available $\mathrm{Ca}^{2+}$ & 43.0 & 35.9 & 25.1 \\
\hline Coating & Yes (x2) & Yes & Yes \\
\hline
\end{tabular}

Note: ${ }^{\mathrm{a} C a l-B o o s t}$ and RumiLife 24 boluses use calcium chloride dihydrate, Transition bolus uses anhydrous calcium chloride.

strips, in order to ensure that the boluses were not causing acidosis. If the entire bolus was dissolved at the time of sample collection, sampling was terminated. Each animal only received one bolus at a time, with a minimum of one full day between tests. Each bolus type was tested a total of three times, meaning that it was tested twice in one animal and once in the other; the decision of which animal received which bolus type twice was made at random.

\section{Absorption of Calcium in Postparturient Cows from Commercial Boluses}

A 380-cow Holstein dairy herd in the province of Quebec, Canada was selected. The study was conducted from November 2019 to March 2020. Cattle were housed in two tie-stall barns for the duration of their lactation, with a third tie stall barn dedicated to the dry and transition cows. Dry cows were moved to this third barn and were fed a dry cow ration. One month prior to their expected calving date, cows were transitioned to a prepartum ration consisting of $20 \mathrm{~kg}$ of grass silage, $5 \mathrm{~kg}$ of dry hay, $0.85 \mathrm{~kg}$ of soybean meal $48 \%$ and a $200-\mathrm{g}$ mineral pack. The mineral concentration of this total ration was as follows: calcium $0.52 \%$ dry mass (DM.), phosphorus $0.33 \%$ DM, magnesium $0.38 \% \mathrm{DM}$, and potassium $2.4 \%$ DM. In midDecember, the potassium in the close-up ration was lowered. The new ration consisted of $7.85 \mathrm{~kg}$ of grass silage, 8 $\mathrm{kg}$ of corn silage, $3 \mathrm{~kg}$ of dry hay, and $4 \mathrm{~kg}$ of a supplement created for this farm. The modified mineral concentrations were calcium $0.56 \% \mathrm{DM}$, phosphorus $0.31 \% \mathrm{DM}$, magnesium $0.50 \% \mathrm{DM}$, and potassium $1.41 \% \mathrm{DM}$. The pre-partum ration was not prepared as a Total Mixed Ration (TMR) and therefore implementing a Dietary Cation-Anion Difference (DCAD) strategy was not deemed a practical option. Each cow was transferred to one of the milking barns the morning following calving.

Only cows in their second and third lactations were enrolled in this study. Because of the high level of potassium in both rations, all older cows (>third lactation) received intravenous calcium at calving to prevent clinical milk fever, sometimes followed by oral calcium supplementation, and were therefore not included in this study. Twenty-seven healthy second- and third-lactation cows with body condition score (BCS) of 2.75-3.5 and an estimated average weight of $767 \mathrm{~kg}$ (second lactation) or 787 $\mathrm{kg}$ (third lactation) were randomly allocated to one of three oral calcium treatment protocols ( 9 cows per group irrespective of parity). Treatment 1 received two high calcium chloride boluses (Cal-Boost Bolus, Solvet Animal Health, Calgary Alberta, Canada) at time 0; Treatment 2 received one high calcium chloride Cal-Boost Bolus (Solvet Animal Health, Calgary Alberta, Canada) at time 0 with a second bolus 12 hours later; and Treatment 3 received two high calcium carbonate boluses (RumiLife CAL24 Bolus, Genex Cooperative Inc, Shawano, Wisconsin, USA) at time 0. Treatments were initiated within 12 hours following calving and this was considered Time $0(\mathrm{t}=0)$. The intermediate calcium chloride/calcium carbonate bolus was excluded from this study as we were most interested in the two extremes (high calcium chloride vs high calcium 
Table 2 Initial Serum Calcium Concentration by Treatment Group

\begin{tabular}{|l|l|l|l|}
\hline & Treatment I & Treatment 2 & Treatment 3 \\
\hline Cows per group & 9 & 9 & 9 \\
\hline Second lactation & 3 & 9 & 6 \\
\hline Third lactation & 6 & 0 & 3 \\
\hline Average, mmol/L & 1.64 & 1.95 & 1.88 \\
\hline Range, mmol/L & $1.26-1.88$ & $1.85-2.23$ & $1.39-2.16$ \\
\hline
\end{tabular}

carbonate). Cows calving between 5:00 p.m. and 5:00 a.m. commenced the protocol at 5:00 am. Cows calving between 5:00 a.m. and 5:00 p.m. started their protocol at 5:00 p.m. Blood was taken in a $10-\mathrm{mL}$ red-topped vacutainer vial from the coccygeal vein pretreatment at time 0 , and at 1 , $6,12,13$, and 24 hours post-treatment. The blood was immediately centrifuged on the farm (3000 rpm, $10 \mathrm{~min}-$ utes) and the serum was transferred into a 3-mL red-topped vacutainer tube for storage at $-18^{\circ} \mathrm{C}$. Total calcium was analyzed by an in-clinic Idexx Catalyst One Chemistry Analyzer. One cow in the Treatment 2 group developed clinical milk fever within 12 hours after receiving the initial bolus and was removed from the study because it did not receive the second bolus. Another cow in Treatment 3 also developed clinical milk fever; however, this was the day after the 24-hour study period and she was therefore included in the trial.

Even though allocation to treatment groups was randomized, there was an age discrepancy between groups. There were more older cows in Treatment 1, which explains the lower Time 0 serum calcium levels (Table 2). Upon analyzing the raw data from the first 27 animals, cows with more severe hypocalcemia had a greater response to oral calcium supplementation than

Table 3 Initial Serum Calcium Concentration in Animals with Severe vs Moderate Hypocalcemia

\begin{tabular}{|l|l|l|}
\hline & $\begin{array}{l}\text { Treatment I, } \\
\text { Severe } \\
\text { Hypocalcemia } \\
(<1.8 \mathrm{mmol} / \mathrm{L})\end{array}$ & $\begin{array}{l}\text { Treatment I, } \\
\text { Moderate } \\
\text { Hypocalcemia } \\
(\geq 1.8 \mathrm{mmol} / \mathrm{L})\end{array}$ \\
\hline Cows per group & 10 & $\mathrm{II}$ \\
\hline Average, mmol/L & 1.57 & 1.91 \\
\hline Range, $\mathrm{mmol} / \mathrm{L}$ & $\mathrm{I} .26-1.76$ & $1.8 \mathrm{I}-2.02$ \\
\hline
\end{tabular}

cows with moderate hypocalcemia. With this new information, it was decided to end the original trial and to evaluate serum response to calcium supplementation depending on whether the cow had moderate $(\geq 1.8$ $\mathrm{mmol} / \mathrm{L})$ or severe $(<1.8 \mathrm{mmol} / \mathrm{L})$ hypocalcemia. The new trial consisted of second and third lactation cows assigned to Treatment 1 . The additional enrollment resulted in 11 animals in the moderate and 10 in the severe hypocalcemia groups as depicted in Table 3.

\section{Statistical Analyses}

Statistical significance was determined based on a mixed model with repeated measures. Multiple comparisons (treatment effects at each time point) were analyzed using Tukey's multiple comparisons test or Sidak's multiple comparisons test. Data were assessed for normality using a Shapiro-Wilk test. The cut-off for significance was $\mathrm{P}<0.05$. The experimental unit was defined as each individual animal. Statistical analyses were carried out in Prism v 8.4.3 (GraphPad Software, San Diego, California, USA).

\section{Results}

\section{In vivo Dissolution Rates of Commercial Calcium Boluses}

The dissolution rate of Bolus 1 (high calcium chloride, no calcium carbonate bolus) was the most rapid of the three calcium boluses tested, with the entire bolus being dissolved before 90 minutes in all three trials (Figure 1 and Table 4). Bolus 2 (intermediate calcium chloride, intermediate calcium carbonate bolus) was slower to dissolve, with complete dissolution by 240 minutes in two trials and 180 minutes in the third (Figure 1 and Table 4). Bolus 3 (low calcium chloride, high calcium carbonate bolus) was very slow to dissolve where, after 240 minutes, $75 \%$ of the original bolus weight was still present (Figure 1 and Table 4). No major fluctuations in rumen $\mathrm{pH}$ were observed over the time course for any of the tested boluses (Table 4).

\section{Absorption of Calcium in Postparturient Cows from Commercial Boluses}

Treatment 2 (the single-dose regimen of high calcium chloride) yielded significantly higher serum calcium levels than Treatment 3 (the double dose of calcium carbonate bolus) at 1 hour, with similar calcium levels over the remainder of the time course (Figure 2). 


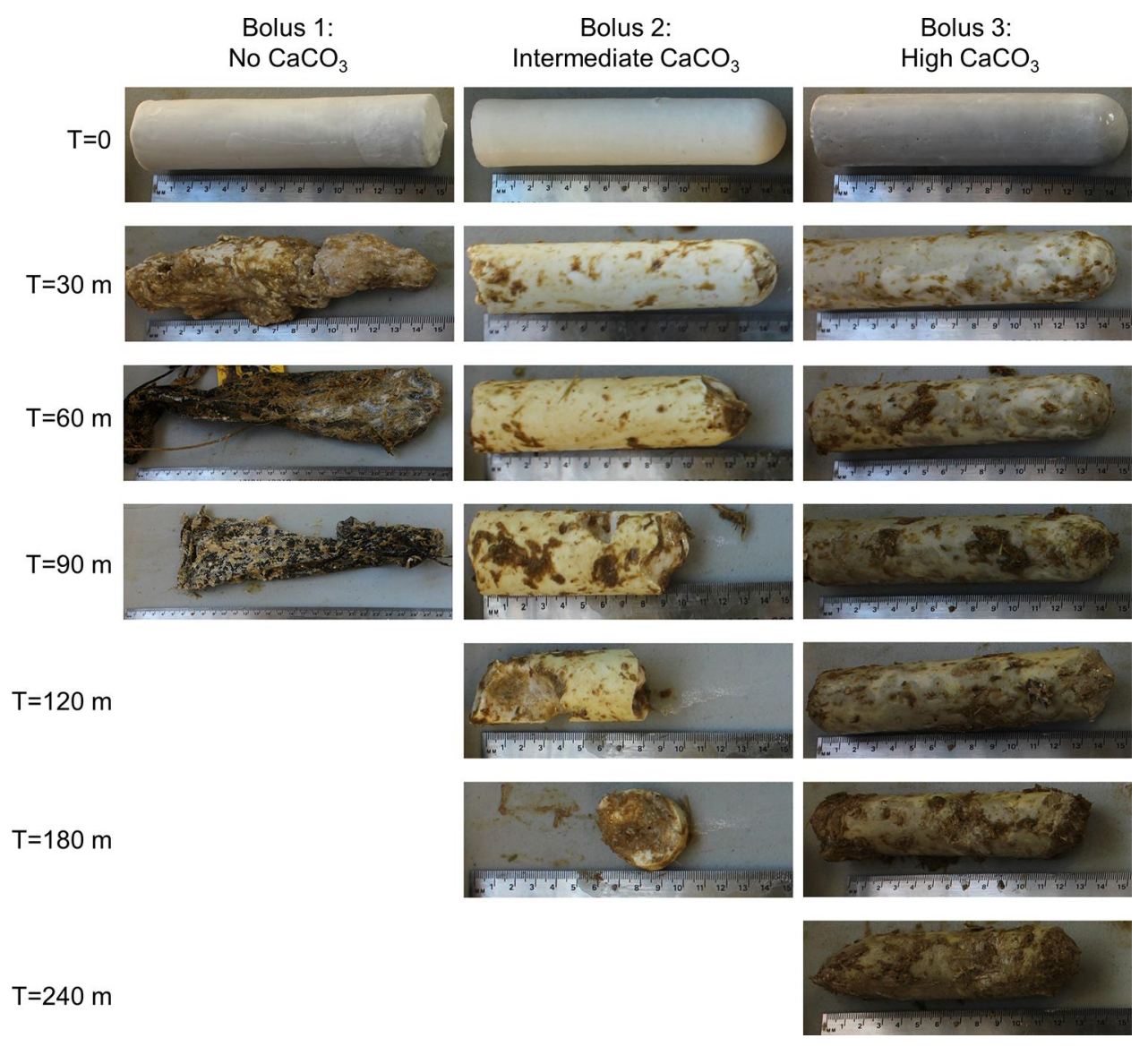

Figure I Dissolution of various calcium boluses in the rumen of fistulated cattle. Representative images of each bolus type are shown for each time point. Note that Bolus I had to be photographed in the recovery net at 30,60 , and 90 minutes due to its compromised structural integrity.

Treatment 1 (the double dose of the High Calcium Chloride bolus) yielded significantly higher serum calcium levels at 1 and 6 hours relative to Treatment 3, with similar levels over the remainder of the time course. Importantly, Treatment 1 yielded significantly higher serum calcium levels over the first 13 hours than Treatment 2 (Figure 2), indicating that two calcium chloride boluses at time 0 lead to a greater increase in serum calcium than the traditional regimen of giving one bolus each at $\mathrm{t}=0$ and $\mathrm{t}=12$ hours.

Table 4 Wet Weights and Rumen pH of Various Calcium Boluses After Incubation in the Rumen of Fistulated Cattle

\begin{tabular}{|c|c|c|c|c|c|c|}
\hline \multirow[t]{2}{*}{ Time (Minutes) } & \multicolumn{3}{|c|}{ Bolus Weight $^{\mathrm{a}}$ (g) } & \multicolumn{3}{|c|}{ Rumen $\mathbf{p H}^{\mathbf{a}}$} \\
\hline & Bolus I & Bolus 2 & Bolus 3 & Bolus I & Bolus 2 & Bolus 3 \\
\hline 0 & $200 \pm 1$ & $189 \pm 5$ & $207 \pm 1$ & $7.58 \pm 0.14$ & $7.5 \pm 0$ & $7.58 \pm 0.14$ \\
\hline 30 & $236 \pm 7$ & $245 \pm 19$ & $256 \pm 6$ & $7.75 \pm 0.35$ & $7.5 \pm 0$ & $7.5 \pm 0$ \\
\hline 60 & $172 \pm 74$ & $213 \pm 19$ & $264 \pm 13$ & $7.58 \pm 0.14$ & $7.5 \pm 0$ & $7.5 \pm 0$ \\
\hline 90 & 0 & $156 \pm 57$ & $25 I \pm 5$ & $7.58 \pm 0.14$ & $7.5 \pm 0$ & $7.33 \pm 0.29$ \\
\hline 120 & & $95 \pm 84$ & $239 \pm 15$ & & $7.5 \pm 0$ & $7.33 \pm 0.29$ \\
\hline 180 & & $30 \pm 40$ & $226 \pm 29$ & & $7.5 \pm 0$ & $7.5 \pm 0$ \\
\hline 240 & & 0 & $|57 \pm|$ & & $7.5 \pm 0$ & $7.5 \pm 0$ \\
\hline
\end{tabular}

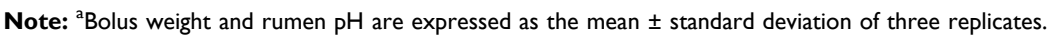




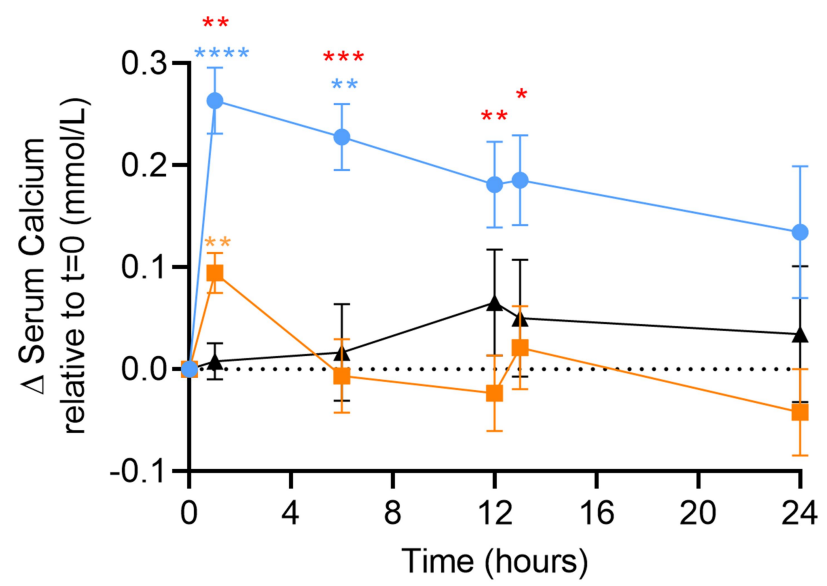

$\rightarrow$ Treatment $1\left(2 \mathrm{CaCl}_{2}\right.$ at $\left.\mathrm{t}=0\right)$

-- Treatment $2\left(1 \mathrm{CaCl}_{2}\right.$ at $\mathrm{t}=0$ and $\left.\mathrm{t}=12 \mathrm{~h}\right)$

$\leftarrow$ Treatment $3\left(2 \mathrm{CaCO}_{3}\right.$ at $\left.\mathrm{t}=0\right)$

Figure 2 Changes in serum calcium upon treatment with commercial boluses. Treatments were initiated within 12 hours following calving (not before) and this time is considered Time $0(\mathrm{t}=0)$. Treatment $\mathrm{I}=$ two high calcium chloride boluses at Time 0 ; Treatment $2=$ one high calcium chloride bolus at $\mathrm{t}=0$ and another at $\mathrm{t}=12$ hours; Treatment $3=$ two high calcium carbonate boluses at $\mathrm{t}=0$. Data represent the mean \pm SEM (standard error of the mean) for 9 independent animals per treatment group. $* \mathrm{P}<0.05 ; * * \mathrm{P}<0.01$; $* * * \mathrm{P}<0.00 \mathrm{I}$, $* * * * \mathrm{P}<0.000 \mathrm{I}$. Blue, orange, and red asterisks denote statistically significant differences between Treatment I vs 3,2 vs 3 , and I vs 2 , respectively.

The severe hypocalcemia cattle had a greater and more persistent response to calcium supplementation than cows suffering from moderate hypocalcemia, with statistically significantly higher serum calcium levels at 6,12 , and 13 hours (Figure 3). The moderately hypocalcemic cows receiving Treatment 1 returned to their baseline value after 24 hours, while severely hypocalcemic cows receiving treatment 1 remained well above their baseline value even after 24 hours (Figure 3). These data suggest that two high calcium chloride boluses administered rapidly after calving are more effective at raising serum calcium compared to the traditional treatment of one bolus followed by a second bolus twelve hours later.

\section{Discussion}

The objectives of this study were to evaluate dissolution times of boluses containing different calcium salts, and their effect on serum calcium in postpartum dairy cows. Calcium chloride and calcium sulfate are absorbed passively through the rumen wall by a process called paracellular absorption. Resistance to movement across the tight junction between epithelial cells can be overcome if the concentration of a mineral, in a freely ionized state, on the luminal side of the tight junction greatly exceeds the

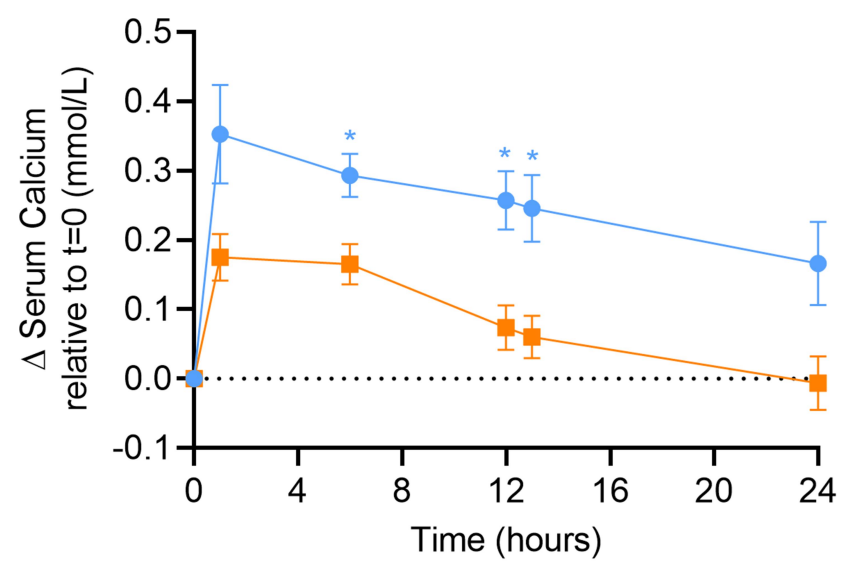

- $2 \mathrm{CaCl}_{2}$ at $\mathrm{t}=0(<1.8 \mathrm{mmol} / \mathrm{L})$

$-2 \mathrm{CaCl}_{2}$ at $\mathrm{t}=0(>1.8 \mathrm{mmol} / \mathrm{L})$

Figure 3 Changes in serum calcium upon treatment with two high calcium chloride boluses (Treatment I) in animals with moderate hypocalcemia $(>1.8 \mathrm{mmol} / \mathrm{L}$ ) versus severe hypocalcemia $(<1.8 \mathrm{mmol} / \mathrm{L})$. Treatments were initiated within 12 hours following calving (not before) and this time is considered Time $0(\mathrm{t}=0)$. Data represent the mean \pm SEM for 10 (severe hypocalcemic cows, treated with 2 high calcium chloride at $\mathrm{t}=0$ ) or II (moderate hypocalcemic cows, treated with 2 high calcium chloride at $\mathrm{t}=0$ ) animals. $* \mathrm{P}<0.05$.

ionized concentration of that mineral in the extracellular fluids within the interstitial space on the other side of the tight junction. ${ }^{17}$ When ionized calcium in the rumen is greater than 6 millimoles (a fivefold increase from the extracellular fluid concentration), the diffusional force created by this difference will be great enough to push the calcium through the tight junction into the interstitial space, and from there it passes through the openings in the capillary endothelium and into the blood. ${ }^{17}$ This process is very rapid and serum calcium will peak in about an hour. Calcium carbonate is absorbed in the duodenum through the cell wall by vitamin D-dependent active transport. Parathyroid hormone (PTH) stimulates the kidneys to produce vitamin D which, in turn, activates the calciumbinding protein and the ATPase pump to transfer calcium ions through the cell wall into the blood. This process has little effect on raising serum calcium levels for at least 6 hours ${ }^{15}$ and this was confirmed in our study. In addition, calcium chloride and calcium sulfate are acidifying agents that increase the sensitivity of receptor cells to PTH. The in vivo dissolution study demonstrates that calcium boluses that contain calcium carbonate dissolve at a slower rate in the rumen. When comparing Bolus 2 and Bolus 3, the concentration of calcium carbonate is a good indicator of the bolus's dissolution rate. The calcium uptake study confirmed that the bolus containing a high concentration of calcium carbonate did not raise serum 
calcium levels before at least 6 hours, even though two boluses were administered at once. Although this high calcium carbonate bolus contains approximately $44 \%$ calcium chloride, this calcium does not appear to be available to the cow before 6 hours. This is an important observation as cows need a rapid supplementation of calcium in the early postpartum period. ${ }^{15}$ The traditional protocol of administering one high calcium chloride bolus shortly after calving followed by a second bolus 12 hours later resulted in a similar two peak graph as reported in a Sampson et al (2009) study. ${ }^{16}$ Notably, the present study compared the traditional protocol (suggested by all brands) of giving one bolus at $\mathrm{t}=0$ and another bolus 12 hours later to the more convenient protocol of giving two boluses at $\mathrm{t}=0$, as the latter approach would be very appealing to a producer. Although it was not surprising that blood calcium peaked at a higher level following an initial dose of two high calcium chloride boluses because of the greater rumen calcium osmolarity, the persistence of this increase was higher than expected. Serum calcium levels were significantly superior to the two-bolus at a 12-hour interval regimen over the first 13 hours and remained numerically higher after 24 hours. When the trial involving Treatment 1 was prolonged to compare the response of cows with severe subclinical hypocalcemia to cows with normal/moderate hypocalcemia, both the serum calcium peak and serum calcium persistence was greater in the severe group. Both calcium chloride and calcium sulfate dissolve rapidly in the rumen. Passive transport of calcium ions between rumen epithelial cells into the extracellular fluid is dependent on diffusion down a concentration gradient. ${ }^{15}$ It stands to reason that the greater the difference between rumen calcium concentration and blood calcium concentration, the more efficient this passive transport will be, thus positively affecting the increase in serum calcium.

Before the arrival on the market of the calcium bolus, cows were commonly drenched with calcium salts. In one trial, various amounts of calcium chloride were administered to hypocalcemic cows as an oral drench. Three different amounts of calcium, provided by calcium chloride, were evaluated. Cows were orally administered either 50,75 or 100 grams of calcium chloride twice within 24 hours. As expected, blood calcium concentrations increased as the doses of calcium chloride increased. However, three hours after the second treatment of 100 grams of calcium, the cow presented signs of severe metabolic acidosis with heavy and deep breathing. A treatment protocol of 75 grams of calcium from calcium chloride twice over 24 hours had no ill effects. ${ }^{15}$ In this study, calcium was provided as a pure calcium chloride solution.

In a more recent trial, cows received 86 grams of calcium for the first 2 days post calving followed by 3 consecutive days of 43 grams. Calcium was provided by triglyceride-coated oral boluses containing a combination of calcium chloride and calcium sulfate. ${ }^{18}$ They determined that the Blood $\mathrm{pH}$ did not differ with administration of oral calcium and averaged 7.488, 7.483, and $7.483 \pm$ 0.012 for 0,43 , and $86 \mathrm{~g}$ of calcium, respectively. Therefore, any negative health effects were not due to metabolic acidosis.

The present study suggests that administering two high calcium chloride/calcium sulfate boluses shortly after calving will be more effective in preventing clinical milk fever than the traditional protocol of one bolus after calving followed by a second bolus twelve hours later. Convenience is a huge factor when it comes to making decisions on the dairy farm and the recommendation to give two boluses 12 hours apart is neither convenient nor management or cow friendly.

Dairy cows experience many metabolic challenges around the time of calving. Some of these cows will experience clinical milk fever (5-10\%), while up to $50 \%$ of mature cows in some herds will show no symptoms but have subclinical hypocalcemia $(\mathrm{SCH}){ }^{9,19}$ Recent studies have shown that chronic $\mathrm{SCH}$ is more damaging to health than transitory $\mathrm{SCH} .{ }^{19,20}$ Our study focused on the serum calcium effects of supplementing calcium. Research conducted in the last decade has shown that $\mathrm{SCH}$ is associated with metabolic diseases, ${ }^{6}$ an increased susceptibility to metritis in the early postpartum period, ${ }^{3,4,6}$ a compromised reproductive performance, ${ }^{7}$ and increased culling rates in the early lactation. ${ }^{8}$ The awareness of the effects of subclinical hypocalcemia in postpartum dairy cows on the farm level has increased thanks to communication efforts by veterinarians and publications. The case for calcium supplementation has been made but many questions are left to answer on timing, composition, benefits, and dosing regimen of these boluses. Oetzel and Miller (2012) found that cows with higher previous lactation mature-equivalent milk production at $105 \%$ of their herd mates, that were supplemented with oral calcium boluses, produced $2.9 \mathrm{~kg}$ more milk at first DHIA (Dairy Herd Information Association) test than similar high producing cows not administered postpartum calcium supplementation. ${ }^{13}$ They also found that lame cows benefited from calcium 
supplementation. Martinez et al (2016) provided calcium boluses on multiple days with more than one bolus given at a time. ${ }^{21}$ High producing cows supplemented with calcium produced 0.8 to $2.7 \mathrm{~kg}$ more milk per day than their high producing peers not supplemented with calcium. They also concluded that supplementing cows with oral calcium reduced the incidence and prevalence of $\mathrm{SCH}$, but that oral calcium increased the incidence of metritis. This negative effect was primarily observed in primiparous cows considered to be at low risk of metritis. However, reproductive performance improved in multiparous cows with this same regimen. Martinez et al (2016) suggested that this multiple-dose treatment regimen for oral calcium should be avoided in primiparous cows and target only populations at high risk of developing hypocalcemia. ${ }^{21}$ Domino et al (2017) found that cows with a high relative herd milk rank, that received calcium either subcutaneously or as a bolus, were almost half as likely as nonsupplemented cows to be diagnosed with mastitis in the first 60 Days in Milk (DIM). ${ }^{22}$ They did not report any other health or production benefits between the control group and the two supplemented groups. Leno et al (2018) researched the effects of a single dose of oral calcium on postpartum plasma calcium concentration in Holstein cows and found that a single dose of an oral calcium bolus did not increase the blood calcium concentration between 1 and 24 hours following administration. ${ }^{12}$ However, responses observed for health and performance outcomes suggest that, in primiparous cows with higher age at first calving or higher body condition score (BCS) at parturition, calcium supplementation positively affected health status and early lactation performance, respectively. ${ }^{12}$ In multiparous cows, supplementation of cows with higher parity, higher BCS, and lameness also resulted in improved health status. Leno suggested that supplementing Ca could alleviate some of the underlying causes of increased risk for metabolic disease in these animals by supporting gut motility, which can be compromised when blood $\mathrm{Ca}$ declines. ${ }^{12}$ Improved gut motility could support a more rapid increase in postpartum intake and lead to a reduction in the rate or severity of metabolic disease, and higher DMI would support greater milk yield in these cows. ${ }^{12}$ For multiparous cows, those with low plasma calcium responded with decreased health disorders but cows with higher plasma calcium had varied responses. The authors concluded that low blood calcium concentration was less reliable than other periparturient risk factors to identify cows with a potential to favorably respond to calcium supplementation.

Target group calcium supplementation strategies have been found to be cost-effective. ${ }^{23}$ A two-bolus regimen, one administered after calving and the second about 24 hours later, was applied to herds following four treatment strategies: lame cows only, high producers only, lame cows and high producers, and all multiparous cows. Although there was a minor herd net impact with the blanket multiparous cow treatment strategy, the greatest return on investment was with the lame cows.

The question remains to be asked whether two boluses at once would be able to amplify these positive responses and whether giving two boluses simultaneously would reduce the number of animals in a herd with a persistent or delayed subclinical hypocalcemia. Giving two boluses at once would negate the need for additional handling (and the accompanying risk of injury to the animal) and likely reduce the behavioral impact of giving boluses the traditional way 12 hours apart. Our study demonstrates that a treatment of two initial high calcium chloride boluses significantly increases blood calcium over the first 13 hours after administration compared to the traditional administration of two boluses at a 12-hour interval. Furthermore, the persistence of these calcium levels remains numerically greater over the 24-hour period. Therefore, the recommendation to provide two boluses at once after calving is practical, convenient, safe, and will more than likely improve the compliance rate of providing the suggested application of two boluses.

A limitation of this study is the lack of blinding of farm personnel to treatments for the first part of the on-farm trial (27 cows) involving two different calcium boluses. However, treatments were administered to cows according to a randomized list prepared before commencement of the study. Farm personnel abided strictly by this list as well as the pre-established blood collection protocol. For the second part of the on-farm trial, all second- and third-lactation cows were administered the same type of bolus (Bolus 1; high calcium chloride) according to the same treatment regimen (two boluses simultaneously, within 12 hours of calving).

\section{Conclusions}

The dissolution study and the serum calcium response study in Quebec clearly demonstrate the complexity of a proper calcium supplementation. Boluses containing calcium carbonate may cause a delayed delivery of calcium 
when it is needed most, and this may ultimately have an impact on the health and wellbeing of the animal. Further research on the impact of calcium carbonate as it relates to the ability and to the timing of a serum calcium increase seems warranted. There are many different calcium boluses on the Canadian market and the dairy producer would likely benefit from the involvement of the herd veterinarian to help design a calcium bolus strategy. This study demonstrated that the increase in total calcium concentrations lasted for 24 hours when two high calcium chloride boluses were administered shortly after calving. Based on our study findings and on a literature review, the recommendation to provide two boluses at once after calving is practical, convenient, safe, and will likely improve the compliance rate of providing the suggested application of two boluses.

\section{Abbreviations}

BCS, body condition score; DCAD, dietary cation-anion difference; DHIA, dairy herd information association; $\mathrm{PTH}$, parathyroid hormone; $\mathrm{SCH}$, subclinical hypocalcemia; TMR, total mixed ration.

\section{Ethics Approval}

The present field-based study was conducted in compliance with the best practice of veterinary care in accordance with the research guidelines set forth by the Canadian Council on Animal Care and was approved by the Institutional Animal Care and Use Committee (Airdrie, Alberta, Canada) and the Lacombe Research and Development Centre Animal Care Committee.

\section{Consent}

The owners provided informed consent for their animals to be used in the present study.

\section{Acknowledgments}

The authors wish to acknowledge the producer and the farm staff responsible for treatment administration, blood sample collection, centrifugation, and storage, as well as the technicians, the researchers, and the dairy animals that contributed to this study.

\section{Author Contributions}

All authors made substantial contributions to conception and design, acquisition of data, or analysis and interpretation of data; took part in drafting the article or revising it critically for important intellectual content; agreed to submit to the current journal; gave final approval of the version to be published; and agree to be accountable for all aspects of the work.

\section{Funding}

The funding of both studies was entirely provided by Solvet Animal Health.

\section{Disclosure}

Dr Walter Verhoef reports personal fees from Solvet Canada, during the conduct of the study; personal fees from Bureau Vétérinaire de Richmond and Solvet Canada, outside the submitted work; is a partner in Bureau Vétérinaire de Richmond, and was consulting for Solvet. Dr Brenda Ralston reports Dr Merle Olson was her Masters supervisor in 2001; they have published numerous other papers and have collaborated on various grants. Dr Joseph A Ross reports compensation paid to his employer (Chinook Contract Research) for time spent writing, preparing figures, and statistical analyses for Alberta Veterinary Laboratories, during the conduct of the study. Dr Merle Olson reports personal fees from Alberta Veterinary Laboratories, during the conduct of the study; receives salary from Solvet, and Sjoert Zuidhof is providing consulting services to Solvet, which markets the CalBoost bolus. The authors report no other potential conflicts of interest for this work.

\section{References}

1. The Merck Veterinary Manual. 8th ed. Harcourt Brace \& Co.; 1998.

2. Curtis CR, Erb HN, Sniffen CJ, et al. Association of parturient hypocalcemia with eight periparturient disorders in Holstein cows. $J$ Am Vet Med Assoc. 1983;183(5):559-561.

3. Martinez N, Risco CA, Lima FS, et al. Evaluation of peripartal calcium status, energetic profile, and neutrophil function in dairy cows at low or high risk of developing uterine disease. J Dairy Sci. 2012;95(12):7158-7172. doi:10.3168/jds.2012-5812

4. Martinez N, Sinedino LD, Bisinotto RS, et al. Effect of induced subclinical hypocalcemia on physiological responses and neutrophil function in dairy cows. J Dairy Sci. 2014;97(2):874-887. doi:10.3168/ jds.2013-7408

5. Daniel RC. Motility of the rumen and abomasum during hypocalcaemia. Can J Comp Med. 1983;47(3):276-280.

6. Rodríguez EM, Arís A, Bach A. Associations between subclinical hypocalcemia and postparturient diseases in dairy cows. J Dairy Sci. 2017;100(9):7427-7434. doi:10.3168/jds.2016-12210

7. Chapinal N, Carson M, Duffield TF, et al. The association of serum metabolites with clinical disease during the transition period. $J$ Dairy Sci. 2011;94(10):4897-4903. doi:10.3168/jds.2010-4075

8. Roberts T, Chapinal N, Leblanc SJ, Kelton DF, Dubuc J, Duffield TF. Metabolic parameters in transition cows as indicators for early-lactation culling risk. J Dairy Sci. 2012;95(6):3057-3063. doi:10.3168/ jds.2011-4937 
9. Reinhardt TA, Lippolis JD, McCluskey BJ, Goff JP, Horst RL. Prevalence of subclinical hypocalcemia in dairy herds. Vet J. 2011;188(1):122-124. doi:10.1016/j.tvj1.2010.03.025

10. Sasidharan V. Prevent milk fever and economic loss with oral calcium supplements. Prog Dairyman. 2014.

11. Goff JP. Macromineral physiology and application to the feeding of the dairy cow for prevention of milk fever and other periparturient mineral disorders. Animal Feed Sci Technol. 2006;126(3-4):237-257. doi:10.1016/j.anifeedsci.2005.08.005

12. Leno BM, Neves RC, Louge IM, et al. Differential effects of a single dose of oral calcium based on postpartum plasma calcium concentration in Holstein cows. J Dairy Sci. 2018;101(4):3285-3302. doi:10.3168/jds.2017-13164

13. Oetzel GR, Miller BE. Effect of oral calcium bolus supplementation on early-lactation health and milk yield in commercial dairy herds. $J$ Dairy Sci. 2012;95(12):7051-7065. doi:10.3168/jds.2012-5510

14. Neves RC, Leno BM, Stokol T, Overton TR, McArt JAA. Risk factors associated with postpartum subclinical hypocalcemia in dairy cows. J Dairy Sci. 2017;100(5):3796-3804. doi:10.3168/ jds.2016-11970

15. Goff JP, Horst RL. Oral administration of calcium salts for treatment of hypocalcemia in cattle. J Dairy Sci. 1993;76(1):101-108. doi:10.3168/jds.S0022-0302(93)77328-2

16. Sampson JD, Spain JN, Jones C, Carstensen L. Effects of calcium chloride and calcium sulfate in an oral bolus given as a supplement to postpartum dairy cows. Vet Ther Fall. 2009;10(3):131-139.

17. Goff JP. Invited review: mineral absorption mechanisms, mineral interactions that affect acid-base and antioxidant status, and diet considerations to improve mineral status. J Dairy Sci. 2018;101 (4):2763-2813. doi:10.3168/jds.2017-13112
18. Martinez N, Sinedino LDP, Bisinotto RS, et al. Effects of oral calcium supplementation on mineral and acid-base status, energy metabolites, and health of postpartum dairy cows. J Dairy Sci. 2016;99(10):8397-8416. doi:10.3168/jds.2015-10527

19. Caixeta LS, Ospina PA, Capel MB, Nydam DV. Association between subclinical hypocalcemia in the first 3 days of lactation and reproductive performance of dairy cows. Theriogenology. 2017;94:1-7. doi:10.1016/j.theriogenology.2017.01.039

20. McArt JAA, Neves RC. Association of transient, persistent, or delayed subclinical hypocalcemia with early lactation disease, removal, and milk yield in Holstein cows. J Dairy Sci. 2020;103 (1):690-701. doi:10.3168/jds.2019-17191

21. Martinez N, Sinedino LDP, Bisinotto RS, et al. Effects of oral calcium supplementation on productive and reproductive performance in Holstein cows. J Dairy Sci. 2016;99(10):8417-8430. doi:10.3168/jds.2015-10529

22. Domino AR, Korzec HC, McArt JAA. Field trial of 2 calcium supplements on early lactation health and production in multiparous Holstein cows. J Dairy Sci. 2017;100(12):9681-9690. doi:10.3168/ jds.2017-12885

23. McArt JA, Oetzel GR. A stochastic estimate of the economic impact of oral calcium supplementation in postparturient dairy cows. $J$ Dairy Sci. 2015;98(10):7408-7418. doi:10.3168/jds.2015-9479

\section{Publish your work in this journal}

Veterinary Medicine: Research and Reports is an international, peerreviewed, open access journal publishing original research, case reports, editorials, reviews and commentaries on all areas of veterinary medicine. The manuscript management system is completely online and includes a very quick and fair peer-review system. Visit http://www.dovepress.com/testimonials.php to read real quotes from published authors. 